\title{
Oito anos de adaptações competitivas na federação paulista de handebol: um estudo documental da categoria sub-14
}

\author{
Lucas Leonardo' \\ Alcides José Scaglia²
}

\section{RESUMO}

A competição configura-se como um cenário em que intervenções podem promover sua transformação num ambiente de aprendizagem. O handebol de jovens do estado de São Paulo configura-se como uma fonte rica para pesquisas, pois são observadas adaptações para competições entre 11 e 14 anos de idade. O objetivo desta pesquisa é analisar as adaptações competitivas de competições sub-14 organizadas pela Federação Paulista de Handebol entre 2011 e 2018 realizada por uma pesquisa documental. Fica evidente o quão complexa é a proposição de modelos competitivos ajustados ao jovem. Estas dificuldades são ilustradas pelas constantes inserções e supressões de itens regulamentares ao longo dos anos. As adaptações defensivas são as mais importantes e são seguidas de conflitos relacionados às situações de desequilíbrio numérico defensivo, uso do goleiro-linha e cobranças de tiros livres, que são associadas ao uso obrigatório da defesa individual e à proibição do uso de defesas 6:0 e mistas.

Palavras-chave: Handebol. Competição. Esportes de jovens. Engenharia competitiva.

1 Mestre em Educação Física e Sociedade. Faculdade de Educação Física da Universidade Estadual de Campinas (FEF/UNICAMP). Campinas/São Paulo, Brasil. E-mail: lucasleo@gmail.com

2 Doutor em Pedagogia do Movimento. Professor curso de Ciências do Esporte na Faculdade de Ciências Aplicadas da Universidade Estadual de Campinas (FCA/UNICAMP). Limeira/São Paulo, Brasil. E-mail: alcides.scaglia@ fca.unicamp.br 
Eight years of competitive adaptations in paulista handball federation: a documentary study of u-14 category

\begin{abstract}
Competition is a context where interventions can promote their transformation into a learning environment. The youth handball in the state of São Paulo is a rich source for research and adaptations are observed for competitions between 11 and 14 years old. The aim of this research is analyze the competitive adaptations of $\mathrm{u}-14$ competitions of the Paulista Handball Federation between 2011-2018 through documentary research. Difficulties are illustrated by the constant insertion and deletion of regulatory items over the years. The defensive adaptations are the most important and are followed by conflicts related to situations of numerical defensive inferiority, fake goalkeeper and free throws, which are associated with the compulsory use of individual defense and the prohibition of the use of 6: 0 and mixed defenses.
\end{abstract}

Keywords: Handball. Competition. Youth sports. Competitive engineering.

Ocho años de adaptaciones competitivas en la federación paulista de balonmano: un estudio documental de la categoría sub-14

\title{
RESUMEN
}

La competición es un cenario en que intervenciones pueden promover su transformación en un ambiente de aprendizaje. El balonmano de jóvenes del estado de São Paulo se configura como una fuente rica para investigaciones, pues se observan adaptaciones para competiciones entre 11 y 14 años de edad. Esta investigación pretende analizar las adaptaciones competitivas realizadas en competiciones sub-14 de la Federacíon Paulista de Balonmano entre 2011 y 2018 realizada por una investigación documental. Dificultades son ilustradas por las constantes inserciones y supresiones de artículos reglamentarios a lo largo de los años. Las adaptaciones defensivas son las más importantes y son seguidas de conflictos relacionados con las situaciones de desequilibrio numérico defensivo, uso del portero-falso y cobranzas de tiros libres, que se asocian al uso obligatorio de la defensa individual ya la prohibición del uso de defensas 6:0 y mixtas.

Palabras clave: Balonmano. Competición. Deportes de jóvenes. Ingeniería competitiva. 


\section{INTRODUÇÃO ${ }^{3}$}

Como elemento inseparável ao esporte, a competição pode ser entendida como um ambiente de aprendizagem esportiva para o jovem atleta (CHOI; JOHNSON; KIM, 2014; CRANE; TEMPLE, 2015), mas para que isso seja possível são necessárias mudanças em sua concepção primária, de modo a transformá-la num cenário mais ajustado às demandas e necessidades de aprendizagem do público jovem, fazendo da competição um espaço que promova uma lógica de progressão de aprendizagem voltada à facilitação do desenvolvimento de competências técnico-táticas em indivíduos cujas habilidades atléticas ainda não estão totalmente desenvolvidas (BERGERON et al., 2015; CÔTÉ; LIDOR; HACKFORT, 2009; ENGEBRETSEN et al., 2010).

Como uma estrutura teórica que apresenta propostas de modificação competitiva para o público jovem, a Engenharia Competitiva propõe que mudanças sejam realizadas nas instalações esportivas (por exemplo, dimensões do campo/quadra, das áreas de jogo, tamanho das traves), materiais esportivos (por exemplo, uso de bolas de tamanho e peso que facilitem ao jovem o acesso ao jogo), estrutura esportiva (competições com diferentes níveis e exigências) e regras do jogo e da competição (por exemplo, promover regras de impulsionem a participação dos jovens jogadores, tais como substituições obrigatórias e regras que não permita que haja grandes diferenças nos placares), para que seja possível que a competição se transforme num ambiente que promova o aumento da ação e pontuação, a manutenção placares próximos, a melhoraria do envolvimento pessoal, a oportunidade de equalização competitiva e a oferta de níveis competitivos ajustados aos interesses e condições de prática do jovem (BURTON; GILLHAM; HAMMERMEISTER, 2011), tendo como alvo jovens que estejam entre os anos de experimentação (6 a 12 anos de idade) e os anos de especialização (13 a 15 anos de idade), segundo Modelo Desenvolvimental de Participação (CÔTÉ; BAKER; ABERNETHY, 2007; CÔTÉ; FRASER-THOMAS, 2007).

O cenário do handebol do estado de São Paulo se apresenta como uma rica fonte para pesquisas sobre modificações realizadas em competições de jovens, por já terem sido observadas e registradas a implementação de ajustes competitivos para jovens em diferentes competições dentro do estado. Como principal entidade promotora do handebol paulista, a Federação Paulista de Handebol (FPHb) tem sido uma das entidades a promover ao longo dos anos propostas regulamentares que apresentam adaptações competitivas para a categoria sub-14 (MENEZEZ, 2010; MENEZES; BOFF; FREIRE., 2014; MENEZES; MARQUES; NUNOMURA, 2015).

Em face a este rico cenário, esta pesquisa tem por objetivo analisar as adaptações competitivas realizadas em competições sub-14 organizadas pela FPHb ao logo dos anos, na busca de viabilizar a transformação do cenário competitivo num ambiente mais ajustado às disposições, necessidades e possibilidades de prática de jovens atletas.

3 Os autores declaram ausência de conflito de interesses de natureza pessoal, comercial, política, acadêmica ou financeira em relação a este estudo. 


\section{MÉTODOS}

\section{Natureza da Pesquisa}

Este é um estudo histórico, de natureza qualitativa e abordagem analítica (YIN, 2016), realizada por meio de pesquisa documental de múltiplos regulamentos de competições de handebol organizados pela FPHb na categoria sub-14.

Documentos se configuram como fontes de informação estáveis cujo enfoque analítico ainda não foi empregado (GIL, 2002), sendo o papel desta pesquisa tratar estas informações brutas em representações que possibilitem facilitar o acesso, consulta e referência aos documentos estudados (BARDIN, 2016).

\section{Coleta de Dados}

A coleta dos regulamentos da categoria sub-14 ocorreu por duas vias: a) acesso à fonte digital primária dos documentos por meio da consulta aos regulamentos diretamente no site oficial da FPHb (ALMEIDA, 2011) e b) recebimento de regulamentos advindos de arquivos pessoais de quatro árbitros e 11 treinadores de handebol atuantes na categoria sub-14 das competições da FPHb. Estes procedimentos possibilitaram a coleta de regulamentos referentes às temporadas do período de 2011 a 2018, totalizando a análise de oito temporadas competitivas.

Como os regulamentos foram coletados de primeira e segunda mãos, optamos por comparar os conteúdos dos documentos coletados para avaliação da confiabilidade dos dados. Os regulamentos foram agrupados por temporada/ano e com auxílio do software QSR NVivo 11.0 comparamos seus conteúdos por meio da análise de cluster por similaridade de palavras, a partir do coeficiente de Pearson. Obtivemos coeficiente 1,00 para todos os regulamentos, constatando total semelhança entre os regulamentos coletados, atestando confiabilidade ao processo de coleta e permitindo segurança para as análises subsequentes.

\section{Análise de conteúdo}

tamos como técnica para obtenção de informações a análise de conteúdo que foi realizada pelo primeiro autor, devido à sua experiência prévia na leitura e interpretação de regulamentos competitivos, sendo adotada as etapas da pré-análise, exploração do material e tratamento dos dados propostos por Bardin (2016).

Em busca estabelecer confiabilidade aos processos empregados adotamos o procedimento de re-teste da análise de conteúdo realizada (MAYRING, 2014). Desta forma, foram realizadas duas análises dos regulamentos coletados, às quais foram separadas por um intervalo de quatro semanas. Ambas foram comparadas por meio do teste Kappa realizado pelo software QSR Nvivo 11.0. A comparação alcançou o valor 1,00 de concordância, 
atestando total estabilidade nas análises e assegurando confiança ao processo de análise de conteúdo empregado.

\section{Procedimentos Éticos}

Esta pesquisa faz parte de um projeto maior aprovado pelo comitê de ética da Universidade Estadual de Campinas sob o número 57799916.1.0000.5404.

\section{Resultados}

A análise de conteúdo dos regulamentos estudados nos permitiu dividir as modificações competitivas em três categorias: a) adaptações defensivas em função do tempo de jogo; b) adaptações para a inferioridade numérica defensiva; e c) adaptações para cobranças de tiros livres.

Com objetivo de sintetizar as adaptações realizadas, foram organizados três quadros que resumem as modificações previstas nos regulamentos da categoria sub-14 da Federação Paulista de Handebol entre os anos de 2011 e 2018, cujos resultados serão apresentados a seguir.

\section{Adaptações defensivas em função do tempo de jogo}

Em 2011 e 2012 os regulamentos determinavam em cada tempo de jogo a utilização da defesa individual seguida da escolha entre defesas zonais abertas ou defesa individual, com proibição ao uso da defesa 6:0 e mista, apresentando pequena variação do tempo total destinado aos sistemas defensivos individuais entre os dois anos.

Entre 2013 e 2015, os regulamentos modificaram-se. A defesa individual tornou-se restrita apenas ao $1^{\circ}$ quarto do jogo, houve inclusão do uso obrigatório das defesas zonais abertas $5: 1$ no $2^{\circ}$ quarto do jogo e $3: 3$ no $3^{\circ}$ quarto do jogo e foi permitida a livre escolha defensiva no $4^{\circ}$ quarto do jogo, mediante proibição do uso das defesas 6:0 e mista em toda partida. 


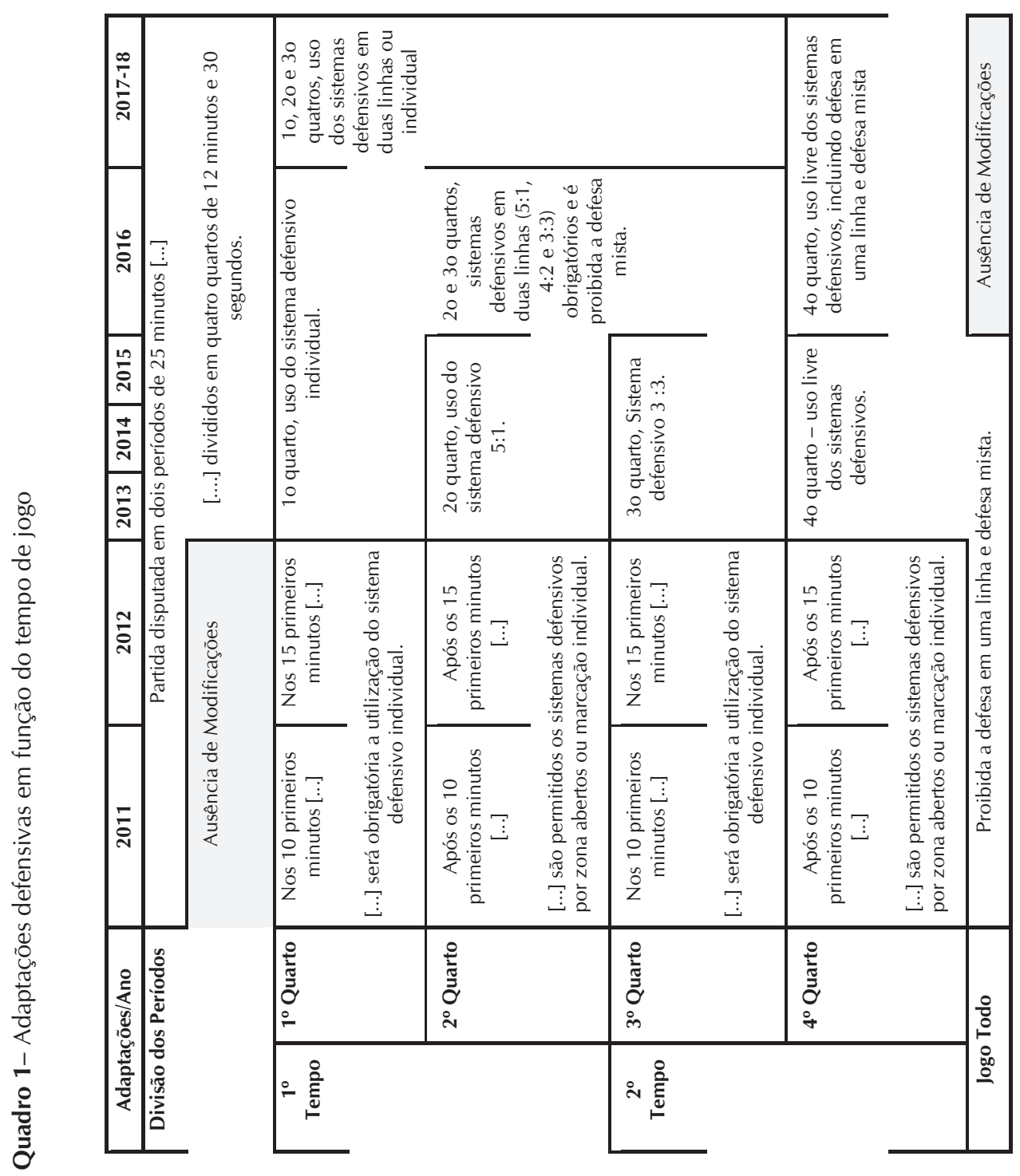


Em 2016, manteve-se o uso da defesa individual apenas no $1^{\circ}$ quarto do jogo. No $2^{\circ}$ e $3^{\circ}$ quartos tornou-se obrigatório o uso das defesas zonais em duas linhas, tendo como opções as defesas 5:1, 4:2 e 3:3, com a proibição ao uso de outros tipos de defesa. Manteve-se a proibição à defesa 6:0 e mista, exceto no $4^{\circ}$ quarto da partida a defesa, em que a escolha era livre, incluindo as defesas 6:0 e mistas.

Desde 2017, o texto regulamentar suprimiu a obrigatoriedade da defesa individual e tornou facultativa nos três primeiros quartos a escolha entre a defesa individual ou as defesas zonais em duas linhas (5:1, 3:3 e 4:2). Foi mantida a liberdade de escolha do sistema defensivo no último quarto do jogo com permissão ao uso da defesa 6:0 ou mista.

\section{Adaptações em inferioridade numérica defensiva}

Em 2011 não constatamos presença de adaptações para momentos de inferioridade numérica defensiva, porém, em 2012, observamos a proibição ao goleiro em atuar como jogador de linha na quadra ofensiva durante a defesa individual obrigatória. Isso evitou, que fosse criada superioridade numérica ofensiva com a utilização do goleiro como um sétimo atacante e manteve-se resguardada a possibilidade de atuação defensiva individual em equilíbrio numérico, conforme observado até 2016.

Também em 2012, durante situações de exclusão e desqualificações (que deixavam as equipes punidas em inferioridade numérica por dois minutos da partida), observamos que no $1^{\circ}$ quarto de jogo era obrigatória a permanência da defesa individual às equipes punidas. No $2^{\circ}$ e $3^{\circ}$ quatros da partida era possível às equipes punidas o uso de defesas em duas linhas (4:1, 3:2 e etc.) e era proibido o uso de defesas alinhadas (5:0, 4:0 e etc.) e mistas $(4+1 ; 3+2$ e etc.).

Entre 2013 e 2015 manteve-se a proibição às defesas alinhadas (5:0, 4:0 e etc.) e mistas $(4+1 ; 3+2$ e etc.) durante todo jogo e abriu-se a possibilidade do uso do sistema defensivo em duas linhas (4:1, 3:2 e etc.) durante a inferioridade numérica defensiva quando a defesa individual era obrigatória no $1^{\circ}$ quarto. Durante o uso exclusivo da defesa zonal em duas linhas no $2^{\circ}$ e $3^{\circ}$ quartos da partida passou a ser obrigatória a manutenção deste tipo de sistema defensivo.

Em 2016, o uso de defesas em uma linha (5:0, 4:0 e etc.) e mistas continuaram proibidas nos três primeiros quartos do jogo, mas no $4^{\circ}$ período o uso de quaisquer sistemas defensivos foi liberado em casos de exclusão ou desqualificação. 


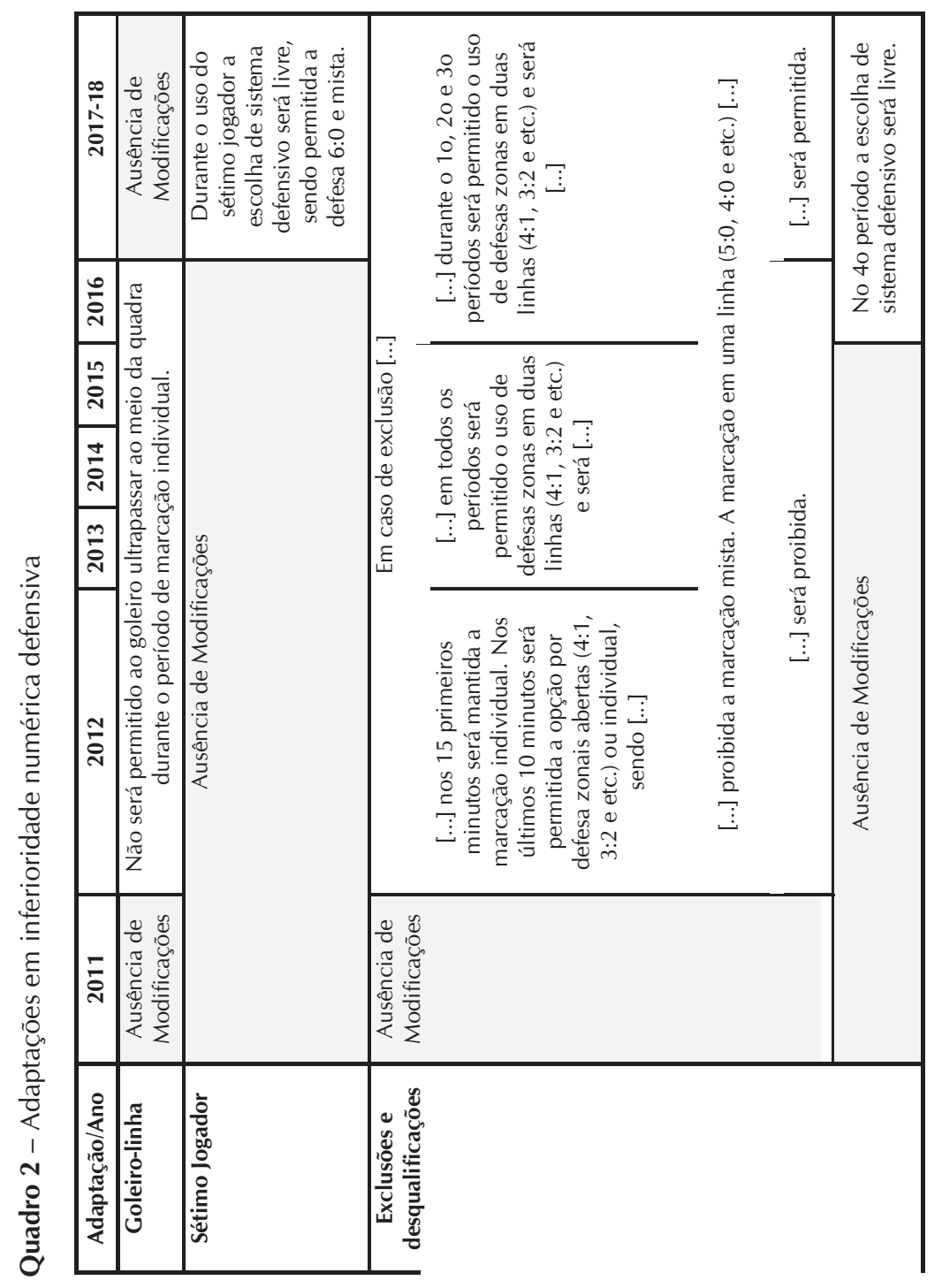


Desde 2017, houve a supressão da proibição ao uso do goleiro-linha com a inclusão da regra do sétimo jogador de quadra, de modo que se tornou possível o uso da defesa 6:0 sempre que o sétimo jogador de quadra fosse utilizado, o que evitaria o jogo ofensivo em vantagem numérica frente às defesas individuais e zonal em duas linhas. $\mathrm{O}$ uso de defesa zonal em uma linha (5:0, 4:0) em casos de exclusões ou desqualificação passou a ser permitida durante todo o jogo.

\section{Adaptações em cobranças de tiros livres}

Em 2011 e 2012, durante a cobrança de tiros livres ocorridas nos momentos de defesa individual obrigatória, os defensores deveriam permanecer com a utilização da defesa individual.

Entre 2013 e 2015, houveram alterações nesta orientação. Passou a ser permitido às equipes que se estruturassem em uma linha próximos aos seis metros, desde que logo após a cobrança do tiro livre os defensores retornassem imediatamente ao uso da defesa individual, o que contrariava, mesmo que momentaneamente, o regulamento deste período que proibia o uso do 6:0 em toda a partida.

Em 2016, durante os três primeiros períodos de jogo, o regulamento proibiu novamente aos defensores que se alinhassem próximo aos seis metros e no $4^{\circ}$ período houve liberação de escolha defensiva durante a cobrança de tiros livres, uma vez que a escolha do sistema defensivo era livre de acordo com o regulamento.

Entre 2011 e 2016 uma orientação presente nos regulamentos tornava evidente mais um problema relacionado ao uso da defesa individual obrigatória em cobranças de tiros livres. Os regulamentes descreviam que era proibido aos atacantes que não participassem da cobrança do tiro livre que se isolassem da ação ofensiva ao se deslocarem para espaços distantes do local da cobrança do tiro livre. Por serem marcados individualmente, isso poderia gerar a abertura de espaços defensivos que poderiam transformar as cobranças de tiros livres em muito efetivas aos atacantes, por permitir configuração de uma situação de $2 \times 2$ em espaços amplos e perigosos da quadra.

Com o fim da obrigatoriedade da defesa individual, verificamos que desde 2017 são retirados dos regulamentos quaisquer orientações defensivas e ofensivas sobre os momentos de cobrança de tiro livre. 


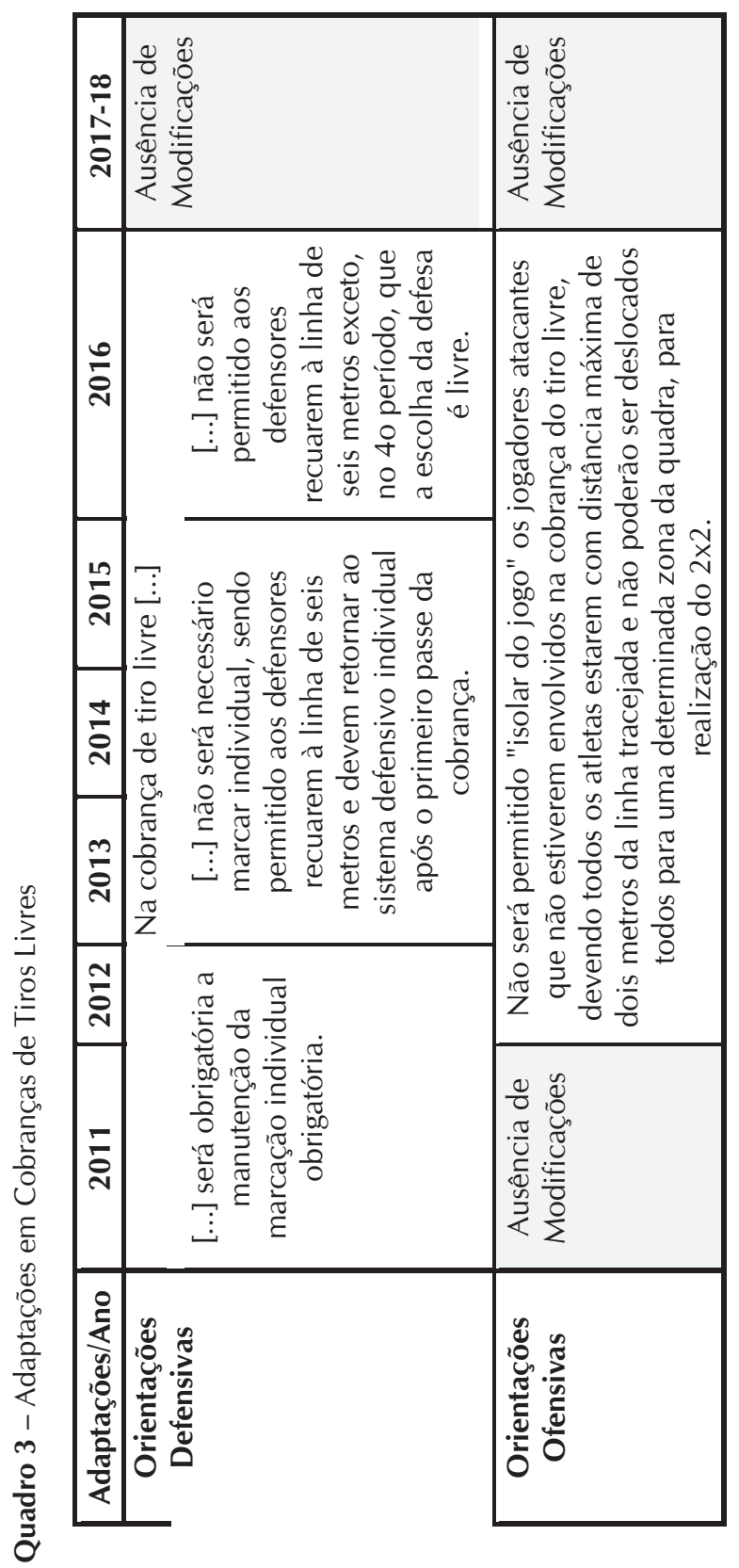




\section{Discussões}

Verificamos que ao longo dos oito anos estudados houve decréscimo de importância do uso da defesa individual, culminando na supressão de sua obrigatoriedade em 2017, tendência acompanhada do ganho de importância das defesas zonais em duas linhas a partir de 2013.

Estas mudanças vão ao encontro às propostas de Ehret et al. (2002) e Greco, Silva e Greco (2012) que orientam a diminuição do tempo destinado ao uso da defesa individual entre 12 e 14 anos de idade e o aumento da importância de defesas zonais em duas ou três linhas, evidenciando que os regulamentos evoluíram de maneira a respeitar esta demanda da formação do jovem atleta.

As defesas em duas ou três linhas sugeridas por estes mesmos autores para estas idades são a 1:5, 3:3, 4:2 e 3:2:1, todas com estruturas abertas devido à prevalência da ocupação do espaço da quadra em profundidade e menor ocupação em largura (SIMÕES, 2002). O uso da defesa 5:1 não aparece entre as sugestões, por ser dentre as defesas abertas aquela com característica mais fechada, porém, a utilização da defesa 5:1 é permitida nos regulamentos estudados desde 2012, apresentando este como um ponto contraditório às propostas que sustentam as modificações competitivas aplicadas ao ambiente do handebol de jovens.

Para Ehret et al. (2002) e Greco, Silva e Greco (2012), as defesas 6:0 e mistas não devem ser enfatizadas na categoria sub-14. Até o ano de 2015 as defesas 6:0 e mistas eram proibidas o jogo todo e apenas a partir de 2016 seu uso passou a ser permitido no último quarto da partida, por ser um período que não apresenta quaisquer modificações competitivas, assemelhando-se do ambiente competitivo formal.

Mesmo sendo um período do jogo bastante restrito, a ausência de adaptações num momento decisivo da partida pode resultar no uso exacerbado de defesas mistas $(5+1$ ou $4+2$ ) sobre os jogadores que se destacam, restringindo que estes atletas tenham liberdade para atuar, uma vez que são isolados das ações ofensivas de sua equipe, característica que nesta idade deve ser secundarizada pela importância de ser estimulada a participação e ação dos jogadores presentes na quadra (BURTON; GILLHAM; HAMMERMEISTER, 2011).

Tendo em vista que após os anos de especialização a aplicação de modificações competitivas diminui em importância (BURTON; GILLHAM; HAMMERMEISTER, 2011), entendemos que a inclusão de um quarto do jogo no qual não sejam presentes modificações possa relacionar-se com a transição para a próxima categoria competitiva, que é disputada dentro da FPHb sem nenhuma modificação regulamentar.

Com intuito de manter esta experiência competitiva, os momentos do jogo com ausência de adaptações competitivas poderiam ser alocados ao $1^{\circ}$ quarto do jogo, resultando na sua aplicação de forma mais coesa com base nas metas de formação do atleta de handebol, reduzindo o caráter decisivo associado à ausência de modificações.

Após serem vivenciadas as adaptações defensivas no ano de 2011, percebemos que em 2012 houve o incremento de modificações no regulamento que estavam relacionadas aos momentos de exclusões, desqualificações e uso do goleiro-linha, nos sugerindo que 
houveram conflitos na aplicação das adaptações defensivas nas situações do jogo com inferioridade numérica defensiva.

Frente às exclusões e desqualificações, entre 2012 e 2016 os regulamentos proibiram o uso de defesas alinhadas (5:0, 4:0 e etc.) e impuseram o cumprimento do regulamento por meio do uso de defesas individuais e em duas linhas quando estas eram obrigatórias.

As defesas individual e zonal em duas linhas se baseiam na simplificação das regras de conduta tática por evidenciar a relação de $1 \times 1$. Estas propostas defensiva ajustam-se às possibilidades de ação do jovem atleta, que nesta faixa etária se manifestam essencialmente por condutas individuais, sendo o equilíbrio numérico fundamental para isso (EHRET et al., 2002).

A desvantagem numérica, oriunda de exclusões e desqualificações impelem aos treinadores de handebol que adotem o uso do sistema defensivo alinhado (5:0, 4:0 e etc.) , independentemente das características da equipe adversária (DEBANNE; LAFFAYE, 2015), demonstrando que o alinhamento defensivo possui íntima relação com a lógica do jogo defensivo realizado durante a inferioridade numérica (SECO, 2006; ESPINA AGULLÓ; PÉREZ TURPIN; CEJUELA ANTA, 2012).

Esta é uma informação fundamental para a organização de regulamentos adaptados destinados ao público jovem, pois a inferioridade numérica defensiva, uma situação corriqueira no handebol, amplia efetivamente o sucesso ofensivo em competições até 14 anos de idade (GARCÍA et al., 2008; GARCÍA-ANGULO; ORTEGA; MENDOZA 2015) e a manutenção das defesas individual ou em duas linhas durante inferioridade numérica defensiva, conforme verificado entre 2012 e 2016, parece contradizer a lógica organizacional do jogo de handebol retratada por Debanne e Laffaye (2015), Seco (2006) e Espina Agulló, Perez Turpin e Cejuela Anta (2012), que sustenta-se na busca do alinhamento defensivo numa estrutura zonal.

A proibição do uso do goleiro-linha entre 2012 e 2016 ocorreu no sentido de manter o equilíbrio numérico e a prevalência da defesa individual obrigatória no $1^{\circ}$ quarto de jogo ao sustentar a necessidade de igualdade numérica entre ataque e defesa, valorizando as modificações previstas nos regulamentos deste período, mas, em se tratando da formação esportiva, proibir que o goleiro possa atuar ofensivamente tende a promover a especialização dos jovens atletas apenas nas funções de proteção do alvo, negligenciando a eles a experiência de construção do jogo ofensivo que faz parte do processo de formação integral do atleta de handebol, inclusive do goleiro. A especialização precoce tem sido amplamente difundida como negativa para o desenvolvimento e a permanência do jovem na prática esportiva na faixa etária deste estudo (CÔTÉ; FRASER-THOMAS, 2008; NORMAND; WOLFE; PEAK, 2017).

Estas informações nos permitem compreender que a presença do goleiro atuando como um sétimo atacante deveria ser permitida, desde que haja a possibilidade de uso da defesa alinhada, cuja estrutura e funcionalidade é percebida por treinadores de handebol como a mais ajustada para situações de inferioridade numérica, aspecto que passa a ser observado a partir de 2017, quando o regulamento passa a permitir o uso de defesas 5:0 e 4:0 em situações de inferioridade numérica defensiva ocasionada por situações de exclusão 
e desqualificação, e uso da defesa 6:0 no caso do uso de sete atacantes, o que permite ao goleiro atuar na fase ofensiva do jogo caso seja necessário.

Isso passa a ser previsto em 2017, por influência da introdução da regra do sétimo jogador, oficializada em julho de 2016 (CONFEDERAÇÃO BRASILEIRA DE HANDEBOL, 2016) que altera o conceito de goleiro-linha. Por ser esta uma regra oficial, sua manutenção torna-se importante em termos competitivos.

A necessidade de que adaptações de regulamento sejam previstas durante as cobranças de tiros livres sustenta-se por este ser um momento do jogo de potencial benefício ofensivo, sobretudo, quando os tiros são cobrados nas proximidades dos nove metros (linha tracejada). Por ser o tiro livre um dos poucos momentos em que as equipes podem organizar o jogo ofensivo partindo de uma situação estável, as cobranças de tiro livre possibilitam a aplicação de ações táticas intencionais em busca de superioridade numérica momentânea para a finalização à distância ou através de penetrações dos atacantes na direção dos seis metros (área do goleiro) (EHRET et al., 2002; GARCÍA, 2015).

Verificamos três mudanças na orientação defensiva para a cobrança do tiro livre ao longo dos oito anos, todas elas frente aos momentos de defesa individual obrigatória.

Para entender motivos que levaram a estes ajustes, é essencial compreender os impactos da orientação inserida a partir de 2012, referente à proibição do jogo de 2x2 durante as cobranças de tiros livres. Segundo o texto regulamentar, era proibido o deslocamento proposital de atacantes não participantes da cobrança de tiros livres para regiões distantes da posição da bola com objetivo de criar amplos espaços vazios na quadra.

Como forma de exemplificar os problemas desta postura ofensiva frente à defesa individual, Siegenthaler e Gonzalez (1997) relatam que em ligas de basquetebol de jovens treinadores manipulam a regra da marcação individual deixando quatro atacantes parados próximos das linhas laterais da quadra, levando consigo seus respectivos defensores, de modo a oferecer ao melhor jogador da equipe a oportunidade de explorar em grandes espaços da quadra a relação de $1 \times 1$, resultando na menor participação dos demais jogadores atacantes e defensores e na concentração do jogo em apenas um atleta.

Esta atitude é contrária à orientação de Fernández Romero et al. (2012), que indicam ser fundamental que ao atacar contra uma defesa individual, a equipe deve buscar a abertura do espaço central da quadra, seguida de ampla mobilidade dos jogadores sem bola, pois assim haverá o pleno desenvolvimento do jogo ofensivo através do passe e vai, cruzamentos, apoios e desmarques.

Caso uma postura semelhante às relatadas por Siegenthaler e Gonzalez (1997) fosse adotada em 2011, 2012 e 2016 durante uma cobrança de tiro livre na proximidade dos nove metros frente à marcação individual obrigatória, os espaços criados na quadra seriam tão amplos que os dois atacantes participantes da cobrança do tiro livre levariam grande vantagem frente aos seus respectivos defensores.

Mediante a possibilidade de ocorrência de situações similares, é plausível que entre 2013 e 2015 houvesse a permissão para que os defensores se alinhassem em seis metros, evitando que fosse recorrente a grande eficiência do jogo de $2 \times 2$ e a concentração do jogo nos jovens percebidos com melhor rendimento esportivo. 
Os regulamentos entre 2013 e 2015 deixam claro que os jogadores deveriam retornar à defesa individual imediatamente após a cobrança do tiro livre. Se, eventualmente este retorno fosse retardado por alguns instantes, a equipe defensora passaria a caracterizar o uso da defesa 6:0, evidenciando um novo problema na aplicação desta modificação do regulamento, pois a equipe faria uso de um sistema defensivo proibido.

Este conflito deixa de ser observado apenas a partir de 2017, quando o regulamento deixa de obrigar o uso da defesa individual mediante a permissão do uso de defesas zonais em duas linhas nos três primeiros quartos do jogo, o que torna desnecessária a inclusão de orientações ofensivas e defensivas em relação à cobrança de tiros livres.

A livre escolha entre os dois sistemas defensivos (individual ou zonal em duas linhas) permite às equipes que optem pela melhor organização defensiva no momento das cobranças de tiros livres. Isso minimiza a possibilidade de que condutas transgressoras advindas do jogo ofensivo transformem este momento do jogo numa situação problemática para a concretização de um ambiente competitivo transformado para o handebol de jovens.

\section{CONCLUSÕES}

Ao analisar estes oito anos de regulamentos da competição sub-14 da FPHb, fica evidente o quão complexa é a proposição de modelos competitivos modificados e ajustados ao jovem. Estas dificuldades são ilustradas pelas constantes inserções e supressões de itens regulamentares entre 2011 e 2018.

Percebemos que as adaptações defensivas estão hierarquicamente colocadas como as mais importantes em termos de ajustes para a formação do jovem atleta de handebol, porém, uma série de conflitos em sua aplicabilidade passam a ser evidenciadas quando, após 2011, ano em que eram previstas apenas modificações defensivas nos regulamentos estudados, surgem itens regulamentares específicos para situações de desequilíbrio numérico defensivo, uso do goleiro-linha e cobranças de tiros livres associadas ao uso obrigatório da defesa individual e à proibição ao uso de defesas 6:0 e mistas.

A maior parte dos conflitos foram resolvidos com o fim do uso obrigatório da defesa individual desde 2017, o que demonstra um longo período para que os ajustes propostos pudessem caminhar num sentido de transformação do ambiente competitivo aos atletas de handebol, embora, questões problemáticas ainda sejam percebidas.

A defesa 6:0 e as defesas mistas, não indicadas para a categoria sub-14, passam a ser permitidas desde 2016 em momentos decisivos da partida, impelindo o jogo para a possível exarcebação do uso de defesas mistas, isolando alguns jogadores em específico numa idade em que a participação ativa deve ser privilegiada.

Em termos de inferioridade numérica defensiva, o uso das defesas alinhadas (5:0 e 4:0), permitidas apenas a partir de 2017, ajustam-se à lógica defensiva do handebol como maneira de minimizar uma situação que já é potencialmente benéfica para o ataque, sendo interessante sua utilização quando ocorrem exclusões, desqualificações e o uso do goleiro-linha/sétimo jogador na categoria sub-14. 
Consideramos que a proposta regulamentar de 2017/2018 representa um avanço, fruto de sete anos de tentativas de promover um ambiente transformado para a competição de jovens atletas de handebol.

Indicamos que em próximas oportunidades de construção deste regulamento, sejam implementadas reformulações ao momento de utilização da defesa 6:0 e a defesa mista, que poderá ser transferido para o primeiro quarto da partida, reduzindo seu potencial decisório para o jogo. Recomendamos também que o sistema defensivo 5:1 passe a ser permitido apenas nos momentos destinados ao uso das defesas 6:0 e mista, pois a defesa 5:1 é ainda bastante fechada, aproximando-se das características do sistema defensivo 6:0 em relação à sua estrutura, mas pode confundir-se com o sistema defensivo misto $5+1$ devido às funções variadas que o jogador avançado da segunda linha defensiva pode adotar, devendo ser proibida durante o uso do sistema defensivo individual e defesas zonais em duas linhas, tipos de defesa que valorizam a criação de espaços mais amplos na defesa.

\section{REFERÊNCIAS}

AGULLÓ, José Julio Espina; TURPIN, José Antonio Pérez; ANTA, Roberto Cejuela. Evolución histórica y táctica de los sistemas de juego defensivos en balonmano en situaciones de d. E-balonmano.com: Revista de Ciencias del Deporte, [s.I], v. 8, n. 2, p.93-104, maio/ago. 2012. Quadrimestral. Disponível em: < http://www.e-balonmano.com/ojs/ index.php/revista/article/view/109> . Acesso em: 29 jun. 2018.

ALMEIDA, Alexandre Gomes de; NASCIMENTO, Claudia Monteiro; DECHECHI, Clodoaldo José. O handebol de areia. In: GRECO, Pablo Juan; ROMERO, Juan José Fernández (orgs.). Manual de Handebol: da iniciação ao alto nível. São Paulo: Phorte, 2012. p. 349-356.

ALMEIDA, Fábio Chang. O historiador e as fontes digitais: uma visão acerca da internet como fonte primária para pesquisas históricas. Aedos: Revista do Corpo Discente da PPGHistória da UFRGS, Porto Alegre, v. 3, n. 8, p.9-30, jan./jun. 2011. Semestral. Disponível em: < http://www.seer.ufrgs.br/index.php/aedos/article/view/16776/11939> . Acesso em: 29 jun. 2018.

ANGULO, Antonio García; ORTEGA, Enrique; MENDOZA, R.. Grado de satisfacción y preferencias de jugadores de balonmano en acciones técnico-tácticas según la categoría de juego. E-balonmano.com: Revista de Ciencias del Deporte, [s.I.], v. 10, n. 3, p.139148, 2014. Quadrimestral. Disponível em: < http://e-balonmano.com/ojs/index.php/ revista/article/view/173/166>. Acesso em: 29 jun. 2018.

BARDIN, Laurence. Análise de conteúdo. São Paulo: Edições 70, 2016.

BERGERON, Michael $\mathrm{F}$ et al. International Olympic Committee consensus statement on youth athletic development. British Journal Of Sports Medicine, [s.I.], v. 49, n. 13, p.843-851, 17 jun. 2015. BMJ. http://dx.doi.org/10.1136/bjsports-2015-094962.

BURTON, Damon; GILLHAM, Andrew D.; HAMMERMEISTER, Jon. Competitive Engineering: Structural Climate Modifications to Enhance Youth Athletes' Competitive 
Experience. International Journal Of Sports Science \& Coaching, [s.I.], v. 6, n. 2, p.201217, jun. 2011. SAGE Publications. http://dx.doi.org/10.1260/1747-9541.6.2.201.

CHOI, Hong Suk; JOHNSON, Britton; KIM, Young K.. Children's Development Through Sports Competition: Derivative, Adjustive, Generative, and Maladaptive Approaches. Quest, [s.I.], v. 66, n. 2, p.191-202, 3 abr. 2014. Informa UK Limited. http://dx.doi.or g/10.1080/00336297.2013.861757.

CÔTÉ, Jean; BAKER, Joe; ABERNETHY, Bruce. Practice and play in the development of sport expertise. In: TENENBAUM, Gershon; EKLUND, Robert Charles (Ed.). Handbook of Sport Psychology. 3. ed. Hoboken (new Jersey): Wiley, 2007. Cap. 8. p. 184-202. CÔTÉ, Jean; FRASER-THOMAS, Jessica. Play, practice, and athlete development. In: FARROW, Damian; BAKER, Joe; MACMAHON, Clare (Ed.). Developing sport expertise: Lesson from theory and practice. New York: Routledge, 2008. Cap. 2. p. 17-28.

CÔTÉ, Jean; FRASER-THOMAS, Jessica. Youth involvement in sport. In: CROCKER, Peter R. E. (Ed.). Sport psychology: a Canadian perspective. Toronto: Pearson Education Canada, 2007. Cap. 11. p. 270-298.

CÔTÉ, Jean; LIDOR, Ronnie; HACKFORT, Dieter. ISSP position stand: To sample or to specialize? Seven postulates about youth sport activities that lead to continued participation and elite performance. International Journal Of Sport And Exercise Psychology, [s.I.], v. 7, n. 1, p.7-17, jan. 2009. Informa UK Limited. http://dx.doi.org/ 10.1080/1612197x.2009.9671889.

CRANE, Jeff; TEMPLE, Viviene. A systematic review of dropout from organized sport among children and youth. European Physical Education Review, [s.I.], v. 21, n. 1, p.114131, 31 out. 2014. SAGE Publications. http://dx.doi.org/10.1177/1356336x14555294. DEBANNE, Thiery; LAFFAYE, Guillaume. Motivational cues predict the defensive system in team handball: A model based on regulatory focus theory. Scandinavian Journal Of Medicine \& Science In Sports, [s.I.], v. 25, n. 4, p.558-567, 28 set. 2014. Wiley. http://dx.doi.org/10.1111/sms.12328.

EHRET, Arno et al. Manual do Handebol: treinamento de base para crianças e adolescentes. Rio de Janeiro: Phorte, 2002.

ENGEBRETSEN, Lars et al. The International Olympic Committee Consensus Statement on age determination in high-level young athletes. British Journal Of Sports Medicine, [s.I.], v. 44, n. 7, p.476-484, 1 jun. 2010. BMJ. http://dx.doi.org/10.1136/bjsm.2010.073122.

GARCÍA, Iván González. El uso táctico del golpe franco en el balonmano. E-balonmano. com: Revista de Ciencias del Deporte, [s.I.], v. 11, n. 1, p.39-54, jan./abr. 2015. Quadrimestral. Disponível em: < http://www.e-balonmano.com/ojs/index.php/revista/ article/view/183>. Acesso em: 29 jun. 2018.

GARCÍA, Javier et al. Estudio de las diferencias en el juego entre equipos ganadores y perdedores en etapas de formación en balonmano. Cultura, Ciencia y Deporte, Murcia, v. 9, n. 3, p.195-200, 2008.

GIL, Antônio Carlos. Como elaborar projetos de pesquisa. 4. ed. São Paulo: Atlas, 2002. GRECO, Pablo Juan; SILVA, Siomara Aparecida; GRECO, Lucas Fernando. O sistema de formação e treinamento esportivo no handebol brasileiro (SFTE-HB). In: GRECO, Pablo 
Juan; ROMERO, Juan José Fernández (orgs.). Manual de Handebol: da iniciação ao alto nível. São Paulo: Phorte, 2012. p. 235-250.

HANDEBOL, Confederação Brasileira de. Orientações às mudanças das regras a partir de 01 de junho. 2016. Tradução de Ésilo de Mello. Disponível em: < http://lhesp. com.br/uploads/newsmade/temp/alteracao_das_regras_2016_21560.pdf $>$. Acesso em: 02 jul. 2018.

HOLT, Nicholas L. et al. A grounded theory of positive youth development through sport based on results from a qualitative meta-study. International Review of Sport and Exercise Psychology, [s.l.], v. 10, n. 1, p.1-49, 4 set. 2016. Informa UK Limited. http:// dx.doi.org/10.1080/1750984x.2016.1180704.

MAYRING, Philipp. Qualitative content analysis: theoretical foundation, basic procedures and software solution. Klagenfurt: Institute Of Psychology And Center For Evaluation And Research, 2014. 143 p. Disponível em: < https://www.ssoar.info/ssoar/handle/ document/39517>. Acesso em: 02 jul. 2018.

MENEZES, Rafael Pombo. O ensino dos sistemas defensivos do handebol: considerações metodológicas acerca da categoria cadete. Pensar A Prática, Goiânia, v. 13, n. 1, p.1-13, 5 maio 2010. Universidade Federal de Goiás. http://dx.doi.org/10.5216/rpp.v13i1.7269.

MENEZES, Rafael Pombo; BOFF, Leonardo Cordeiro; FREIRE, Vitor Daronco. Processo de ensino-aprendizagem-treinamento do sistema defensivo 3:3 no handebol diante de cruzamentos e trocas de postos específicos ofensivos. Arquivos em Movimento, Rio de Janeiro, v. 11, n. 1, p.5-20, jan./jun. 2015. Disponível em: < https://revistas.ufrj.br/ index.php/am/article/view/9248 >. Acesso em: 29 jun. 2018.

MENEZES, Rafael Pombo; MARQUES, Renato Francisco Rodrigues; NUNOMURA, Myrian. $O$ ensino do handebol na categoria infantil a partir dos discursos de treinadores experientes. Movimento (ESEFID/UFRGS), [s.I.], v. 21, n. 2, p.463-477, 11 mar. 2015. Universidade Federal do Rio Grande do Sul. http://dx.doi.org/10.22456/19828918.47664 .

NORMAND, Jonathan Michael; WOLFE, Andrew; PEAK, Kayla. A Review of Early Sport Specialization in Relation to the Development of a Young Athlete. International Journal Of Kinesiology And Sports Science, [s.I.], v. 5, n. 2, p.37-42, 30 abr. 2017. Australian International Academic Centre. http://dx.doi.org/10.7575/aiac.ijkss.v.5n.2p.37.

ROMERO, Juan José Fernández et al. Sistemas de jogo no ataque. In: GRECO, Juan Pablo; ROMERO, Juan José Fernández (Orgs.). Manual de Handebol: da iniciação ao alto nível. São Paulo: Phorte, 2012. Cap. 14. p. 189-201.

SECO, Juan de Dios Román. Los inicios del siglo XXI: Evolución y tendencias del juego.

E-balonmano.com: Revista de Ciencias del Deporte, [s.I.], v. 2, n. 1, p.3-29, 2006. Quadrimestral. Disponível em: <http://www.e-balonmano.com/ojs/index.php/revista/ article/view/7 > . Acesso em: 29 jun. 2018.

SIEGENTHALER, Kim L.; GONZALEZ, G. Leticia. Youth Sports as Serious Leisure. Journal Of Sport And Social Issues, [s.l.], v. 21, n. 3, p.298-314, ago. 1997. SAGE Publications. http://dx.doi.org/10.1177/019372397021003006. 
SIMÕES, Antônio Carlos. Handebol defensivo: conceitos técnicos e táticos. São Paulo: Phorte, 2002.

YIN, Robert K. Pesquisa qualitativa do início ao fim. Porto Alegre: Penso, 2016.

Recebido em: Junho/2017

Aprovado em: Outubro/2017 